\title{
On equilibrium structures of the water molecule
}

Attila G. Császár, Gábor Czakó, and Tibor Furtenbacher

Department of Theoretical Chemistry, Eötvös University,

H-1518 Budapest 112, P.O. Box 32, Hungary*

Jonathan Tennyson

Department of Physics and Astronomy, University College London, Gower Street, London WC1E 6BT, United Kingdom

Viktor Szalay

Crystal Physics Laboratory, Research Institute for Solid State Physics and Optics, Hungarian Academy of Sciences, H-1525 Budapest, P.O. Box 49, Hungary

Sergei V. Shirin and Nikolai F. Zobov

Department of Physics and Astronomy, University College London, Gower Street, London WC1E 6BT, United Kingdom;

Permanent address: Institute of Applied Physics, Russian Academy of Science, Uljanov Street 46, Nizhnii Novgorod, Russia 603950

Oleg L. Polyansky

Sektion Spektral und Strukturdokumentation, University of Ulm, Helmholtzstrasse 22, D-89069 Ulm, Germany;

Permanent address: Institute of Applied Physics, Russian Academy of Science, Uljanov Street 46, Nizhnii Novgorod, Russia 603950

(Dated: March 25, 2005) 


\begin{abstract}
Equilibrium structures are fundamental entities in molecular sciences. They can be inferred from experimental data by complicated inverse procedures which often rely on several assumptions, including the Born-Oppenheimer approximation. Theory provides a direct route to equilibrium geometries. A recent high-quality ab initio semiglobal adiabatic potential energy surface (PES) of the electronic ground state of water, reported by Polyansky et al. (Science 2003, 299, 539) and called CVRQD here, is analysed in this respect. The equilibrium geometries resulting from this direct route are deemed to be of higher accuracy than those that can be determined by analyzing experimental data. Detailed investigation of the effect of the breakdown of the Born-Oppenheimer approximation suggests that the concept of an isotope-independent equilibrium structure holds to about $3 \times 10^{-5} \AA$ and $0.02^{\circ}$ for water. The mass-independent (Born-Oppenheimer) equilibrium bond length and bond angle on the ground electronic state PES of water is $r_{\mathrm{e}}^{\mathrm{BO}}=0.95782 \AA$ and $\theta_{\mathrm{e}}^{\mathrm{BO}}=$ $104.485^{\circ}$, respectively. The related mass-dependent (adiabatic) equilibrium bond length and bond angle of $\mathrm{H}_{2}{ }^{16} \mathrm{O}$ is $r_{\mathrm{e}}^{\mathrm{ad}}=0.95785 \AA$ and $\theta_{\mathrm{e}}^{\mathrm{ad}}=104.50_{0}{ }^{\circ}$, respectively, while those of $\mathrm{D}_{2}{ }^{16} \mathrm{O}$ are $r_{\mathrm{e}}^{\text {ad }}$ $=0.95783 \AA$ and $\theta_{\mathrm{e}}^{\mathrm{ad}}=104.49_{0}{ }^{\circ}$. Pure $a b$ initio prediction of $J=1$ and 2 rotational levels on the vibrational ground state by the CVRQD PESs is accurate to better than $0.002 \mathrm{~cm}^{-1}$ for all isotopologs of water considered. Elaborate adjustment of the CVRQD PESs to reproduce all observed rovibrational transitions to better than $0.05 \mathrm{~cm}^{-1}$ (or the lower ones to better than $0.0035 \mathrm{~cm}^{-1}$ ) does not result in noticable changes in the adiabatic equilibrium structure parameters. The expectation values of the ground vibrational state rotational constants of the water isotopologs, computed in the Eckart frame using the CVRQD PESs and atomic masses, deviate from the experimentally measured ones only marginally, especially for $A_{0}$ and $B_{0}$. The small residual deviations in the effective rotational constants are due to centrifugal distortion, electronic, and non-Born-Oppenheimer effects. The spectroscopic (nonadiabatic) equilibrium structural paremeters of $\mathrm{H}_{2}{ }^{16} \mathrm{O}$, obtained from experimentally determined $A_{0}^{\prime}$ and $B_{0}^{\prime}$ rotational constants corrected empirically to obtain equilibrium rotational constants, are $r_{\mathrm{e}}^{\mathrm{sp}}=0.95777 \AA$ and $\theta_{\mathrm{e}}^{\mathrm{sp}}=104.48^{\circ}$.
\end{abstract}

*Electronic address: csaszar@chem.elte.hu 


\section{INTRODUCTION}

The Born-Oppenheimer (BO) approximation [1-3] introduces the separation of nuclear and electronic motions and is the single most important concept in our understanding of almost all of molecular sciences, especially that of chemistry. This is due to the fact that the Born-Oppenheimer approximation defines the concept of an electronic potential energy (hyper)surface (PES) [4-6]. Potential energy (hyper)surfaces, which in the standard approximation are mass-independent, are mathematically defined as total energies of species with respect to their geometric variables responsible for the internal motions. Adiabatic corrections [7-11] to the BO-PES relax the strict separation of electronic and nuclear degrees of freedom, defining an adiabatic (mass-dependent) PES. Many molecular processes and properties, discussed routinely, only have meaning within the Born-Oppenheimer approximation and for the resulting (adiabatic) PESs. The most important of these is arguably the equilibrium structure, corresponding to the molecular configuration at the very bottom of a potential well [12-22]. The equilibrium structure is the subject of the present study, employing water, a triatomic molecule of highest relevance, as an example. For a brief historical review of some of the most relevant determinations [23-32] of the mass-independent, and, in cases, mass-dependent, equilibrium structure of the water molecule see Table 1. It is clear that by the 1940s, when Herzberg published his influential epic on rovibrational spectra [24], the structure of water was known with remarkable precision. Nevertheless, the arduous task of moving beyond this precision has proved to be nontrivial even for such a small and simple triatomic molecule.

In an excellent review entitled "Determination of reliable structures from rotational constants" [13], Demaison and co-workers set the standards as "reliable structures [are] structures with an uncertainty less than 0.2 degrees for the angles and $0.002 \AA$ for the distances". This standard of accuracy seems to be at least one order of magnitude less than the expected precision of adiabatic equilibrium structures deduced from high-quality ab initio calculations. It is also well known that there are intrinsic and sizeable differences between the equilibrium $\left(r_{\mathrm{e}}\right)$ structures and the experimentally derived $r_{\mathrm{a}}, r_{\alpha}, r_{\mathrm{c}}, r_{\mathrm{g}}, r_{\mathrm{m}}, r_{\mathrm{s}}, r_{\mathrm{z}}$, etc. structures [13, 16-18, 33]. Several excellent summaries of the approximate relationships between the large number of observable structures and the equilibrium structure exist $[13,18,33,34]$. For example, one of the best compromise when gas-phase electron diffraction (GED) and millimeterwave (MW) spectroscopy are used jointly for structure refinement is a temperature-dependent $r_{\mathrm{g}}$ structure. Due to the fact that the approximate ("diatomic") relation $r_{\mathrm{e}}-r_{\mathrm{g}}=(3 / 2) a u^{2}$ holds reasonably well, where $a$ is the usual Morse parameter $[16,35]$ and $u$ is the vibrational amplitude of the bond concerned, the difference between

the $r_{\mathrm{e}}$ and $r_{\mathrm{g}}$ distance types, as well as between $r_{\mathrm{e}}$ and any vibrationally averaged distance type, is substantial, on the order of $0.01 \AA$.

To arrive at spectroscopic equilibrium structures an inverse, perturbative approach is widely employed [36]. As part of this procedure the accurately measured ground vibrational 
state effective rotational constants are corrected, principally by vibration-rotation interaction constants of different origin and order, and equilibrium geometries are deduced from the resulting equilibrium rotational constants. This inverse procedure can be employed to fairly large molecules, see, e.g., a recent study on the 17-atom amino acid proline [37]. Nevertheless, the ultimate accuracy of this route to equilibrium geometries, which starts from experimental observables (effective rotational constants) and corrects them with appropriate constants, has proved to be, in some sense, insufficient, as diatomic paradigms have shown [38-40].

A direct, fully $a b$ initio approach comes to the rescue. It starts with first-principles computation of equilibrium geometries. The ultimate accuracy of this direct approach has so far been realized (see, e.g., Refs. [19, 38-40]) only for diatomic and few-electron triatomic [41] cases due to the incompleteness of most presently applicable computational approaches. Nevertheless, with recent significant advances in electronic structure theory and computer hardware, the goal of achieving high precision for mass-independent (Born-Oppenheimer) as well as mass-dependent (adiabatic) equilibrium geometries has become possible even for many-electron systems, as shown here.

In the direct approach comparison with experiment is difficult, in fact impossible if only the equilibrium structure has been determined $a b$ initio. If the same level of theory was used to compute a PES, comparison between computed and experimental transition frequencies, most importantly rotational transitions on the ground vibrational state, becomes feasible. Another possibility for comparison between theory and experiment is provided at the level of vibrationally averaged spectroscopic quantities, determined here as the appropriate expectation values using variational vibrational wave functions. The direct approach is helped in the latter case by the fact that close-to-exact solution of the vibrational motion problem, especially for triatomic species, is straightforward to achieve [42, 43, 45]. Both approaches for comparison are pursued in this paper. One must remember, nevertheless, that theory going beyond the diagonal Born-Oppenheimer correction, i.e., consideration of non-BO effects, is still in its infancy and that the so-called experimental spectroscopic constants are effective parameters, obtained through phenomenological approaches which parametrize the Hamiltonian as flexibly as needed. The subtle relation between the spectroscopic and the Born-Oppenheimer and adiabatic equilibrium structures is not completely clear, as also exemplified in this study.

In a recent publication [42] some of us presented $a b$ initio adiabatic PESs of the ground electronic state of water which yielded, for the first time for a polyatomic and polyelectronic molecule, so-called spectroscopic accuracy, $1 \mathrm{~cm}^{-1}$, on average for all measured rovibrational levels of all isotopologs considered. This remarkable precision could not have been obtained without the intrinsic $a b$ initio determination of highly accurate, mass-dependent equilibrium structures of water. In this paper we provide a detailed analysis of our ab initio results for the equilibrium structures of water (Table 2). Water is probably the only polyatomic molecule besides $\mathrm{H}_{3}^{+}$for which adiabatic PESs of almost ultimate accuracy are available. 


\section{COMPUTATIONAL DETAILS}

In this study the DOPI [43, 44], where DOPI stands for discrete variable representation (D) - Hamiltonian in orthogonal (O) coordinates - direct product (P) basis - iterative (I) diagonalization [45], and the DVR3D [46] program suites, both employing a discrete variable representation (DVR) for all three vibrational degrees of freedom, have been employed for the determination of the $J=0,1$ and 2 rovibrational energy levels. Highly converged wave functions were obtained during the nuclear motion calculations, the rovibrational eigenvalues from the two programs, employing somewhat different formalisms, agreed with each other to better than $10^{-3} \mathrm{~cm}^{-1}$.

The nuclear masses employed in the variational nuclear motion calculations are given in footnote $a$ to Table 3 . For the calculation of vibrationally averaged rotational constants atomic masses have been used.

\section{THE $A B$ INITIO CVRQD POTENTIAL ENERGY SURFACE OF WATER}

The high-accuracy semiglobal adiabatic ab initio ground electronic state PESs of the water isotopologs, utilized heavily in this study, were first described in Ref. [42]. Since few details are provided in that publication, the potentials are discussed here briefly, giving reference also to the codes employed in their computation. Components of this ab initio potential, denoted as CVRQD throughout this paper, were obtained as follows: (a) the final PES is built upon aug-cc-pVXZ $[47,48], X=4,5$, and 6 , valence-only internally contracted multi-reference configuration interaction (ICMRCI) [49] calculations, extrapolated to the complete basis set limit (CBS), over a grid containing more than 350 points, employing the program package MOLPRO [50]; (b) added to this is the core correlation correction surface of Partridge and Schwenke [31], determined at a different set of points at the averaged coupled pair functional (ACPF)[51] level employing the program MOLPRO; (c) added to this is a relativistic correction surface obtained by first-order perturbation theory as applied to the one-electron mass-velocity (MV) and one- and two-electron Darwin terms (MVD2) [52-56], calculated using the program packages ACESII [57, 58] and DALTON [59], supplemented by a correction obtained from the inclusion of the Breit term in the electronic Hamiltonian and using four-component Dirac-Hartree-Fock wave functions, utilizing the program package BERTHA [60, 61]; (d) added to this is a correction surface due to effects from quantum electrodynamics (QED) [62, 63], in particular the one-electron Lamb shift, determined by a simple scaling procedure [64]; and (e) finally, adding to this the adiabatic correction surface obtained at the MRCI level [42]. It should also be noted that a non-adiabatic correction was also employed in Ref. [42] for the calculation of (ro)vibrational band origins, based on a twoterm adjustment of the vibrational kinetic energy operator [42, 65] employing parameters taken from a ground-breaking study by Schwenke [66]. 
Because of an often favorable error compensation between incompleteness of the basis set and deficiencies in the treatment of electron correlation, as well as use of approximate Hamiltonians [6, 54, 67], lower-level electronic structure computations often result in surprisingly small errors for a particular property. This useful practical approach is not pursued here as, instead, this study focuses on the convergence of electronic structure theory to obtain the best technically possible equilibrium geometries of the isotopologs of water. Therefore, the large number of results from intermediate levels of theory, a few of which are given in Table 2, are not utilized directly in this study. Note finally that $a b$ initio computation of equilibrium geometries is a somewhat unbalanced procedure [68] due to the almost complete cancellation of two large terms of opposite sign, the approximate electronic and the possibly exact nuclear first derivatives, contributing to the vanishing forces at equilibrium.

\section{THE DIRECT COMPUTATIONAL ROUTE TO BORN-OPPENHEIMER AND ADIABATIC EQUILIBRIUM STRUCTURES}

The direct route to the computation of accurate, converged Born-Oppenheimer and adiabatic equilibrium structures employs systematically improved levels of electronic structure theory. This is due to the fact that for polyelectronic systems none of the limits of ab initio electronic structure theory [6] can be reached without some sort of extrapolation and approximation. As detailed in Section III, the ultimate mass-independent (Born-Oppenheimer) equilibrium structure of water, with an $\mathrm{OH}$ bond length of $r_{\mathrm{e}}^{\mathrm{BO}}=0.95782 \AA$ and a $\mathrm{HOH}$ bond angle of $\theta_{\mathrm{e}}^{\mathrm{BO}}=104.48_{5}{ }^{\circ}$, has been determined [42] from a large set of often expensive $a b$ initio electronic structure computations, relying in part on well-established extrapolation and approximation techniques. These computations result in a point-wise representation of the ground electronic state PES of water. Consequently, the Born-Oppenheimer and adiabatic equilibrium structural parameters of the water isotopologs, reported throughout this paper, have been obtained by interpolations employing fitted PESs [42]. The use of this procedure means that six-digit accuracy in the $a b$ initio determination of the equilibrium structural parameters of the isotopologs of water cannot be expected.

The convergence of the valence-only ICMRCI treatment with respect to the one-particle basis set expansion is relatively fast ( $c f$. Table 2). Even more important for the purposes of the present study are the incremental contributions to the equilibrium structure of water, also listed in Table 2. The significant contribution of core correlation to the equilibrium structure of water is not at all surprising [69, 70]. The related results of Martin [70], obtained at a less complete level of theory, seem to provide a slight underestimation of the core correlation effect for the bond length. Accuracy on the order of $10^{-4} \AA$ in $r_{\mathrm{e}}$ can only be achieved if relativistic effects are taken into account. For $\theta_{\mathrm{e}}$, due to the more substantial change in the electronic structure of water upon bending, relativistic effects have more than half of the contribution of core correlation. This is in line with what 
has been observed during computational investigations of the barrier to linearity of water $[67,71,72]$. Note also the opposite sign of the core correlation and relativistic contributions, resulting in an improved apparent accuracy of the valence-only treatment. The adiabatic contribution, while almost negligible for the equilibrium bond length, is substantial for the bond angle. Even consideration of quantum electrodynamic effects, namely the one-electron Lamb shift [64], has a noticable contribution to the bond angle, in the sixth significant digit, at the border of the claimed precision of the present study. In summary, the direct approach, though computationally expensive, provides a way to obtain highly accurate BornOppenheimer and adiabatic equilibrium structures in a controlled way.

Table 4 summarizes the effects of isotopic substitution on the equilibrium structures of the water isotopologs. It is clear from this table, and from Table 2, as well, that the concept of mass-independent (Born-Oppenheimer) equilibrium geometries seems to be valid for water to about $3 \times 10^{-5} \AA$ and $0.02^{\circ}$. It is also clear, and it reflects simple intuition, that the effect of $\mathrm{H}$ to $\mathrm{D}$ substitution is much larger than that accompanying the ${ }^{16} \mathrm{O}$ to ${ }^{18} \mathrm{O}$ change. Note also that the intrinsic adiabatic contributions to the $r\left({ }^{16} \mathrm{OH}\right)$ and $r\left({ }^{16} \mathrm{OD}\right)$ equilibrium bond length are positive (Table 2) and negative (Table 4), respectively, and on the order of $10^{-5} \AA$. Therefore, this intrinsic adiabatic effect is about two orders of magnitude smaller than the easily explicable substantial negative $r_{0}(\mathrm{OH}) \rightarrow r_{0}(\mathrm{OD})$ change in the vibrationally averaged distance.

Note, finally, that at the all-electron aug-cc-pCVQZ CCSD(T) level, which gains its usual very high accuracy [73, 74] from favorable error compensation, the optimized structural parameters, $r_{\mathrm{e}}^{\mathrm{BO}}=0.95810 \AA$ and $\theta_{\mathrm{e}}^{\mathrm{BO}}=104.48_{1}{ }^{\circ}$, deviate very little, $3 \times 10^{-4} \AA$ and $0.00_{4}{ }^{\circ}$, from the ultimate $r_{\mathrm{e}}^{\mathrm{BO}}$ and $\theta_{\mathrm{e}}^{\mathrm{BO}}$ of this study.

Overall, we feel confident that the ab initio structural parameters of water, based on the CVRQD PESs of Ref. [42], should be nearly exact in the Born-Oppenheimer and adiabatic limits.

\section{ROTATIONAL EIGENVALUES}

As mentioned above, ultimately the accuracy of the $a b$ initio equilibrium structure(s) of water can be probed most directly and meaningfully by computing the observable rotational levels with the aid of the related PESs computed at the same level of theory.

The CVRQD adiabatic PESs reproduce excellently the lowest rotational levels for the isotopologs of water considered, $\mathrm{H}_{2}{ }^{16} \mathrm{O}, \mathrm{H}_{2}{ }^{17} \mathrm{O}, \mathrm{H}_{2}{ }^{18} \mathrm{O}$, and $\mathrm{D}_{2}{ }^{16} \mathrm{O}$. The levels corresponding to the rotational quantum numbers $J=1$ and 2 are collected in Table 3 and exemplify this statement. The $J=1$ term values deviate from the experimentally determined ones [75-78] by less than $0.001 \mathrm{~cm}^{-1}$. The maximum deviation for the $J=2$ CVRQD term values is $0.003 \mathrm{~cm}^{-1}$. The related mean and maximum deviations for the fitted potential of Ref. [79], obtained through elaborate adjustment of the CVRQD PESs to all observed 
rovibrational levels of several isotopologs of water to better than $0.05 \mathrm{~cm}^{-1}$, are very similar. The minuscule differences between the CVRQD ab initio and the fitted rotational term values should not be regarded as estimates of the uncertainty in the $a b$ initio prediction of the structural parameters of the water isotopologs as (a) adjustment of the CVRQD PESs was performed with equal weights for low- and high-energy regions and thus the fit was affected very little by the lowest part of the PES; and (b) as part of this work, direct inclusion of linear terms in the PES, representing changes in the equilibrium structure of water, was tested with using a variety of spectroscopic data; the fits all proved to be divergent. The latter statement holds not only for the adjustment of the CVRQD PESs but also for the best previous spectroscopic PES of $\mathrm{H}_{2}{ }^{16} \mathrm{O}$ [32]. Furthermore, note that many of the $J=2$ CVRQD and fitted variational results bracket the experimental term values. This means that it is highly unlikely that any fitting attempt to reproduce the rotational term values even more accurately by a fitted PES will result in any significant change in the adiabatic equilibrium structures of water. To wit, 201 experimental levels for the (000), (100), (010), and (001) states of $\mathrm{H}_{2}{ }^{16} \mathrm{O}, \mathrm{H}_{2}{ }^{17} \mathrm{O}$, and $\mathrm{H}_{2}{ }^{18} \mathrm{O}$ were included in a separate fit that resulted in a standard deviation of only $0.0035 \mathrm{~cm}^{-1}$. Since no linear terms were included in the fit, the related adiabatic equilibrium structural parameters are the same as in the CVRQD PESs, namely $r_{\mathrm{e}}^{\mathrm{ad}}\left({ }^{16} \mathrm{OH}\right)=r_{\mathrm{e}}^{\mathrm{ad}}\left({ }^{17} \mathrm{OH}\right)=r_{\mathrm{e}}^{\mathrm{ad}}\left({ }^{18} \mathrm{OH}\right)=0.95785 \AA$ and $\theta_{\mathrm{e}}^{\mathrm{ad}}\left(\mathrm{H}^{16} \mathrm{OH}\right)=\theta_{\mathrm{e}}^{\mathrm{ad}}\left(\mathrm{H}^{17} \mathrm{OH}\right)=$ $\theta_{\mathrm{e}}^{\mathrm{ad}}\left(\mathrm{H}^{18} \mathrm{OH}\right)=104.50_{0}{ }^{\mathrm{o}}$.

Precision of the $a b$ initio prediction of higher $J$ transitions by the CVRQD PESs is exceptionally good, as well.

\section{SPECTROSCOPIC EQUILIBRIUM STRUCTURES}

Vibrationally averaged effective rotational constants are the principal structural results obtained from fitting of appropriate effective rovibrational Hamiltonians [80-86] to spectroscopic data. One can recover these effective constants from theoretical rovibrational computations basically in two ways. The traditional route goes through second-order vibrational perturbation theory (VPT2) formulas and the lowest-order vibration-rotation interaction constants $\alpha_{i}$, obtained from a cubic force field expansion of the PES [35, 87-91]. The difference between the effective and the equilibrium rotational constants is approximated in this indirect route as a sum of vibration-rotation interaction constants. The resulting spectroscopic equilibrium structural parameters are denoted here collectively as $r_{\mathrm{e}}^{\mathrm{sp}}$ and $\theta_{\mathrm{e}}^{\mathrm{sp}}$, though, as detailed below, several meaningful variants can be defined. Note that centrifugal distortion terms need to be considered before the experimental rotational constants are converted into ground-state moments of inertia for structure analysis [81, 85]. These corrected rotational constants are usually referred to as $A^{\prime}, B^{\prime}$, and $C^{\prime}$. In the alternative, direct route one computes the effective rotational constants as expectation values employing vibrational wave functions from converged variational nuclear motion calculations. It is important to 
emphasize that pure vibrational wave functions for triatomic molecules can be determined with little numerical effort $[43,45]$. Following the second route provides the vibrational difference between effective and equilibrium rotational constants. This second, direct route is recommended for computation of vibrationally averaged rotational constants whenever its use is feasible. To obtain effective rotational constants following the second route one should use coordinates given in the Eckart system of axes since effective rovibrational Hamiltonians employed during fitting of experimental spectra are derived this way [92, 93]. In this case the inertia tensor $\mathbf{I}$ is not diagonal, and the rotational constants are calculated by vibrational averaging of the diagonal elements of $\mathbf{I}^{-1}$. Consideration of the Coriolis contribution results in change in only one of the rotational constants, $C$ [94]. The significant difference between the principal axes system (PAS) and Eckart coordinate system vibrationally averaged rotational constants for water, employing up to sextic force field representations of the PES, has recently been demonstrated [43]. First-principles vibrationally averaged rotational constant results of this study, obtained in coordinates in the Eckart system and by inclusion of the Coriolis contribution, are given in Table 5.

It is instructive to compare the vibrational corrections obtained from the direct variational approach to those computed from the indirect, traditional approach, based on VPT2. To facilitate this comparison we computed the VPT2 vibrational corrections to the groundstate rotational constants of $\mathrm{H}_{2}{ }^{16} \mathrm{O}$ from the best, empirically adjusted $a b$ initio vibrationrotation interaction constants of Ref. [95], corresponding to a refined anharmonic force field and thus representing an excellent set of physically meaningful constants obtained through VPT2. These values, as well as the spectroscopic results from Ref. [25] are also given in Table 5. By comparing the spectroscopic and the $a b$ initio $\Delta A, \Delta B$, and $\Delta C$ values, where, e.g., $\Delta B$ stands for the difference between the vibrationally averaged and the equilibrium $B$ values, it becomes clear that the spectroscopic values [25] are much closer to the high-quality variational predictions of this study than the $a b$ initio values derived from the vibrationrotation interaction constants of Ref. [95]. In fact, the largest discrepancy between the spectroscopic [25] and the present $a b$ initio CVRQD values is $560 \mathrm{MHz}$ for $\Delta A$, while it is $3270 \mathrm{MHz}$ between the spectroscopic and the perturbational (VPT2) ab initio results. Note that for prototypical semirigid molecules, for which there is at least two orders of magnitude difference between vibration-rotation interaction constants of consecutive order, the vibration-rotation interaction constants can be computed straightforwardly from the vibrationally averaged rotational constants of the lowest vibrational states. However, for water, for which the corresponding difference is less than tenfold, this procedure does not result in accurate lowest-order vibration-rotation interaction constants.

The computed and measured ground-state inertia defects $\left(\Delta_{\mathrm{pl}}^{0}\right)$ of the planar water molecule exemplify further the difficulties in comparing measured and computed effective constants (Table 5). The inertia defect of $\Delta_{\mathrm{pl}}^{0}=0.05064 \mathrm{u} \AA^{2}$ corresponds to rotationvibration constants obtained in Ref. [25]. The inertia defect corresponding to one of the most recent set of effective ground-state rotational constants [96] is $0.05092 \mathrm{u} \AA^{2}(0.0515$ 
$\mathrm{u} \AA^{2}$ with the uncorrected rotational constants). If the rotation constants are not corrected for distortion terms, the corresponding inertia defect is $0.05149 \mathrm{u} \AA^{2}$, in good agreement with the above number. However, if the rotation constants are corrected for distortion terms, the inertia defect becomes substantially smaller, $0.04864 \mathrm{u} \AA^{2}$ [82]. The computed CVRQD and VPT2 values are 0.04613 and $0.04631 \mathrm{u} \AA^{2}$, respectively. At the same time the underlying computed CVRQD and VPT2 $\Delta A$ and $\Delta C$ constants deviate from each other substantially. The CVRQD $\Delta A$ and the VPT2 $\Delta C$ constants are close to their respective spectroscopic counterparts while the remaining two constants disagree by as much as 10$20 \%$. Note that for water the largest contribution to $\Delta_{\mathrm{pl}}^{0}$, almost $90 \%$, comes from $\Delta C$. The sizeable differences between the VPT2 and the variational CVRQD $\Delta A, \Delta B$, and $\Delta C$ values call attention to the fact that the accuracy of semispectroscopic equilibrium structures, i.e., those obtained through corrections of experimental rotational constants by ab initio VPT2 vibration-rotation interaction constants, an approach [37, 89, 97] gaining popularity, might be compromised when high accuracy is sought, on the order of $10^{-4} \AA$ for bond lengths, for small and light species.

There are two plausible explanations for the small but significant remaining discrepancies observed for the measured, the variationally computed, and the VPT2 $A_{0}, B_{0}$, and $C_{0}$ constants of Table 5. The first one recalls that the spectroscopic constants, though apparently of very high precision, are phenomenological in nature and incorporate several "small" effects. It is clearly demonstrated by the data of Table 5 that $\Delta A, \Delta B$, and $\Delta C$ corrections computed from an excellent cubic force field representation of the PES of water [95] are rather inaccurate. It is also clear that centrifugal distortion effects are extremely large in water $[36,82]$. The other explanation suggests that the remaining differences between the computed CVRQD and the spectroscopic ground-state rotational constants are due to shortcomings of the theory, related principally to three factors. First, though the CVRQD PESs are of very high accuracy, they are still not the ultimate adiabatic PESs of water isotopologs and minor improvements of the adiabatic potentials are feasible. Second, no account of the presence of electrons in the molecule is given, coupling of the electronic angular momentum with the overall rotation of the nuclear framework [98] has not been considered and, consequently, no electronic contributions to the effective rotational constants have been computed. Third, it must be investigated whether non-adiabatic effects [65, 66], not considered so far explicitly and the hardest to ascertain, have a noticable contribution.

To investigate the first possible theoretical shortcoming the latest semispectroscopic, fitted PES of water [79] has been employed in the expectation value calculations with results presented in Table 5. The smallness of the adjustments to the lower part of the fully $a b$ initio CVRQD PES is demonstrated repeatedly in this study by the excellent agreement between the CVRQD and the fitted effective rotational constant results. The maximum unsigned deviation is only $90 \mathrm{MHz}\left(0.003 \mathrm{~cm}^{-1}\right)$, while the mean deviation is only on the order of $20 \mathrm{MHz}$. The small changes in the ground-state rotational constants are due to the slightly different form of the wave function (see Section V). Therefore, further improvement 
of the $a b$ initio PES of Ref. [42] through fitting to observed transitions does not seem to hold promise in obtaining significant changes in the values of the rotational constants.

Next, let us investigate effects due to the presence of electrons in the molecule. They can be approximated most easily through changes in the masses of the nuclei, most importantly that of $\mathrm{H}$, in the nuclear motion calculations. Two related comments. First, using atomic masses $M^{\beta}=m^{\beta}+Z^{\beta} m_{\mathrm{e}}$ or scaled atomic masses [99] in computations, where $m^{\beta}$ and $Z^{\beta}$ are the nuclear mass and atomic number of atom $\beta$, respectively, and $m_{\mathrm{e}}$ is the electronic mass, corresponds to absorbing some part of the nonadiabatic effect into the adiabatic approximation. Second, atomic rather than nuclear masses are employed in analysis of molecular spectra. Table 6 contains equilibrium distances and angles of water isotopologs obtained from using either experimental $A_{0}^{\prime}$ and $B_{0}^{\prime}$ or CVRQD ground-state effective rotational constants corrected with the seemingly dependable CVRQD or experimental $\Delta A$ and $\Delta B$ constants. ( $\Delta A$ and $\Delta B$ constants do not depend noticably on whether nuclear or atomic masses were used during their evaluation.) The results obtained show that use of experimental vs. CVRQD constants changes the equilibrium structural parameters substantially, $r_{\mathrm{e}}\left({ }^{16} \mathrm{OH}\right)$ by up to $0.00024 \AA$ and $\theta_{\mathrm{e}}\left(\mathrm{H}^{16} \mathrm{OH}\right)$ by up to $0.017^{\circ}$. The best spectroscopic equilibrium structure of water is $r_{\mathrm{e}}^{\mathrm{sp}}=0.95777 \AA$ and $\theta_{\mathrm{e}}^{\mathrm{sp}}=104.48^{\circ}$.

As to electronic contributions related to the rotational $g$-factor $[36,98]$, they are usually regarded to be small. This general wisdom can be checked for water as it is one of the few polyatomic systems for which the electronic effect has been known for quite some time $[100,101]$ and the underlying [98] rotational $g$-tensor elements have been verified repeatedly [102, 103]. Based on data in Refs. [100, 101], the electronic corrections to $\mathrm{H}_{2}{ }^{16} \mathrm{O}\left(\mathrm{D}_{2}{ }^{16} \mathrm{O}\right)$ are as follows: $\Delta_{\mathrm{A}}^{\mathrm{el}}=294(91) \mathrm{MHz}, \Delta_{\mathrm{B}}^{\mathrm{el}}=168(42) \mathrm{MHz}$, and $\Delta_{\mathrm{C}}^{\mathrm{el}}=99(26) \mathrm{MHz}$. The corrections are considerably smaller for $\mathrm{D}_{2}{ }^{16} \mathrm{O}$ than for $\mathrm{H}_{2}{ }^{16} \mathrm{O}$ since they basically scale linearly both with the $g$-factors and with the effective values of the rotational constants. This fact is partially responsible for the apparently higher accuracy of the effective rotational constant predictions of $\mathrm{D}_{2}{ }^{16} \mathrm{O}$ as compared to $\mathrm{H}_{2}{ }^{16} \mathrm{O}$. These corrections, when added to the computed CVRQD $A_{0}$ and $B_{0}$ constants, not affected by Coriolis effects, largely bridge the experimental - computational deviations. To wit, for $\mathrm{H}_{2}{ }^{16} \mathrm{O}\left(\mathrm{D}_{2}{ }^{16} \mathrm{O}\right)$ the $A_{0}$ deviations decrease from 393(195) to $99(104) \mathrm{MHz}$, while the $B_{0}$ deviations decrease from 219(85) to 51(43) MHz. On the other hand, the electronic correction increases the deviation between the measured and computed results for $C_{0}$. Note that correcting the rotational constants for electronic effects changes $r_{\mathrm{e}}\left({ }^{16} \mathrm{OH} /{ }^{16} \mathrm{OD}\right)$ by $-0.00024 /-0.00009 \AA$ and $\theta_{\mathrm{e}}\left(\mathrm{H}^{16} \mathrm{OH} / \mathrm{D}^{16} \mathrm{OD}\right)$ by $-0.017 /-0.000^{\circ}$.

In summary, none of the factors considered so far seem to be able to eliminate completely the gap between the variationally computed theoretical and the spectroscopic ground-state rotational constants. Iterative refinement of the CVRQD ab initio PES through fitting to observed rovibrational levels does not seem to be able to reduce the discrepancies between computed and experimental rotational constants. Consideration of the electronic effects does not make the discrepancies between the $a b$ initio and the spectroscopic ground- 
state rotational constants vanish though serves to reduce them substantially. Nevertheless, combination of these effects, especially centrifugal distortion correction of the experimental effective rotational constants and electronic effects on the computed rotational constants make the apparent discrepancies between the exceedingly high quality $a b$ initio rotational constant predictions and experiment comfortably small.

Finally, one must address the effect of nonadiabaticity [38-40, 104-107] on the equilibrium structure of water, though at present time, apart from $\mathrm{H}_{3}^{+}$and perhaps water, this can be done only for diatomics with substantial confidence.

It has been shown for light diatomic hydrides, namely for $\mathrm{LiH}, \mathrm{BeH}, \mathrm{BH}$, and $\mathrm{CH}^{+}[38-$ $40,105]$ that the nonadiabatic effect, defined, in a somewhat strange sense, as the difference between the adiabatic equilibrium bond length and that obtained from spectroscopy, i.e., from the experimental fitted effective molecular rotational constant, is substantial for the equilibrium bond lengths. In fact, for $\mathrm{BH}$ and $\mathrm{CH}^{+}$the nonadiabatic correction is estimated $[38,40]$ this way to be large and similar in magnitude, +0.00234 and $+0.00275 \AA$, respectively, while the well-defined adiabatic corrections appear to be considerably smaller, on the order of $+0.00065 \AA$. For the heavier hydrides the nonadiabatic distance correction seems to decrease in magnitude, e.g., for NH it is estimated to be less than $0.00070 \AA$ [40]. Nevertheless, as widely appreciated, the adiabatic correction decreases just as fast or faster, for $\mathrm{NH}$ the adiabatic correction on $r_{\mathrm{e}}^{\mathrm{BO}}$ is estimated to be $+0.00027 \AA$ [40]. Thus, based on results on these diatomic paradigms one can assume that the adiabatic (DBOC) effect is small for $r_{\mathrm{e}}$ of the diatomic radical $\mathrm{OH}$ and similarly in $\mathrm{H}_{2} \mathrm{O}$. This is supported by results in Table 2, where the adiabatic correction for $r_{\mathrm{e}}$ of $\mathrm{H}_{2}{ }^{16} \mathrm{O}\left(\mathrm{D}_{2}{ }^{16} \mathrm{O}\right)$ is only $+0.00003(+0.00001)$ A.

One somewhat striking result for $r_{\mathrm{e}}(\mathrm{OH})$ of water must be mentioned. For the pairs $\mathrm{XH} / \mathrm{XD}$, with $\mathrm{X}=\mathrm{Be}, \mathrm{B}, \mathrm{C}$, and $\mathrm{N}$, it has been clearly established that $r_{\mathrm{e}}^{\mathrm{ad}}(\mathrm{XH})>r_{\mathrm{e}}^{\mathrm{ad}}(\mathrm{XD})$ $[38-40]$. For example, $r_{\mathrm{e}}^{\mathrm{ad}}\left({ }^{12} \mathrm{CH}\right)=1.11806 \AA$ and $r_{\mathrm{e}}^{\mathrm{ad}}\left({ }^{12} \mathrm{CD}\right)=1.11792 \AA[108]$, whereas $r_{\mathrm{e}}^{\mathrm{BO}}\left({ }^{12} \mathrm{CH}\right)$ appears to be [39] $1.11777 \AA$. The present calculations support this trend, in water $r_{\mathrm{e}}^{\mathrm{ad}}\left({ }^{16} \mathrm{OH}\right)=0.95785 \AA$ vs. $r_{\mathrm{e}}^{\mathrm{ad}}\left({ }^{16} \mathrm{OD}\right)=0.95783 \AA$. For the spectroscopic equilibrium bond lengths the trend for the XH species appears to be the same, for example [39, 108, 109], $r_{\mathrm{e}}^{\mathrm{sp}}\left({ }^{12} \mathrm{CH}\right)=1.11979 \AA$ vs. $r_{\mathrm{e}}^{\mathrm{sp}}\left({ }^{12} \mathrm{CD}\right)=1.11888 \AA$. Nevertheless, for $r_{\mathrm{e}}^{\mathrm{sp}}$ one finds an opposite result for the $\mathrm{OH}$ radical [110], $r_{\mathrm{e}}^{\mathrm{sp}}\left({ }^{16} \mathrm{OH}\right)=0.96963 \AA<r_{\mathrm{e}}^{\mathrm{sp}}\left({ }^{16} \mathrm{OD}\right)=0.96968 \AA$, i.e., the ${ }^{16} \mathrm{OD}$ correction is $+0.00005 \AA$. As Table 6 shows, in water $r_{\mathrm{e}}^{\mathrm{sp}}\left({ }^{16} \mathrm{OD}\right)<r_{\mathrm{e}}^{\mathrm{sp}}\left({ }^{16} \mathrm{OH}\right)$ in all cases considered. This apparent discrepancy can be resolved by noting that the spectroscopic data for $\mathrm{OH}$ and $\mathrm{OD}$ [110] were determined in different ways. New experimental work [111, 112] and perhaps an accurate computational determination of adiabatic corrections to $r_{\mathrm{e}}$ should help clarifying this issue. In summary, the nonadiabatic effect on $r_{\mathrm{e}}\left({ }^{16} \mathrm{OH}\right)$ seems to be significant, as can be judged by comparing $r_{\mathrm{e}}^{\mathrm{ad}}\left({ }^{16} \mathrm{OH}\right)=0.95785 \AA$ and $r_{\mathrm{e}}^{\mathrm{sp}}\left({ }^{16} \mathrm{OH}\right)=0.95777$ $\AA$. No similar result can be derived for $r_{\mathrm{e}}\left({ }^{16} \mathrm{OD}\right)$ as no corresponding experimental $A_{0}^{\prime}$ and $B_{0}^{\prime}$ rotational constants are available to us.

The diatomic paradigms provide no estimate for the adiabatic equilibrium bond angle 
correction. Fortunately, there seems to be very little uncertainty ( $c f$. Table 6) in the equilibrium bond angle of the water isotopologs. The changes in $\theta_{\mathrm{e}}$ occuring upon using different rotational constants and correction factors are minuscule, the data presented in Table 6 suggest that we do know $\theta_{\mathrm{e}}$ of water for almost five significant digits.

\section{CONCLUSIONS}

Equilibrium structures are fundamental entities in molecular sciences yet they are inferred from experimental data by complicated procedures which often rely on several assumptions, including the Born-Oppenheimer approximation. Theory provides a direct route to equilibrium geometries. In this paper, on the example of water, we have explored the direct computational route to the various equilibrium structures of nonlinear polyelectronic and polyatomic systems. In accordance with well-established diatomic paradigms [104], three equilibrium structure types have been deduced, namely Born-Oppenheimer (mass-independent), adiabatic (mass-dependent), and spectroscopic (nonadiabatic) structures. The former two equilibrium structure types have clear physical meaning, they are based on the concept of potential energy surfaces. Spectroscopic equilibrium structures are less well defined and they correspond to effective spectroscopic constants, derived by fitting an effective Hamiltonian, preferably that given by Watson [80], to appropriate regions of the rovibrational spectrum of water and corrected for centrifugal and perhaps electronic distortion effects.

It is shown that state-of-the-art electronic and nuclear motion calculations, when allowance is made for their coupling, are capable of producing equilibrium structures for polyatomic systems somewhat more accurate than any of the experimental/empirical procedures. In particular, the mass-independent (Born-Oppenheimer) equilibrium structure of the ground electronic state of water is found to be $r_{\mathrm{e}}^{\mathrm{BO}}(\mathrm{OH})=0.95782 \AA$ and $\theta_{\mathrm{e}}^{\mathrm{BO}}(\mathrm{HOH})$ $=104.485^{\circ}$. The concept of mass-independent equilibrium geometries seems to be valid to about $3 \times 10^{-5} \AA$ and $0.02^{\circ}$ for water. The adiabatic, i.e., mass-dependent, equilibrium structural parameters are $r_{\mathrm{e}}^{\mathrm{ad}}\left({ }^{16} \mathrm{OH}\right)=0.95785 \AA$ and $\theta_{\mathrm{e}}^{\text {ad }}\left(\mathrm{H}^{16} \mathrm{OH}\right)=104.500^{\circ}$ for $\mathrm{H}_{2}{ }^{16} \mathrm{O}$ and $r_{\mathrm{e}}^{\mathrm{ad}}\left({ }^{16} \mathrm{OD}\right)=0.95783 \AA$ and $\theta_{\mathrm{e}}^{\mathrm{ad}}\left(\mathrm{D}^{16} \mathrm{OD}\right)=104.490^{\circ}$ for $\mathrm{D}_{2}{ }^{16} \mathrm{O}$. It is believed that these equilibrium structural parameters should be nearly exact both in the Born-Oppenheimer and adiabatic limits, conservative error limits are $\pm 0.00010 \AA$ and $\pm 0.010^{\circ}$.

Our fully $a b$ initio adiabatic CVRQD PESs [42], incorporating equilibrium geometries some of which are reported above, reproduce the $J=1$ and 2 rotational term values of four isotopologs of water with an average accuracy of $0.002 \mathrm{~cm}^{-1}$. A laborious adjustment of the $a b$ initio CVRQD PESs, with equal weights for the low- and high-lying rovibrational states, results in only a minuscule improvement of these rotational frequency predictions. Inclusion of linear terms of the PES in the fitting, representing changes in the equilibrium structure of water, resulted in divergent refinement attempts. These observations indicate that refinements of the presently available high-accuracy ab initio adiabatic PESs of water 
[42], even if the refinement would be geared toward the lowest-lying levels, are unlikely to offer improvements on the underlying adiabatic equilibrium structural parameters. Adiabatic effects are small for the structural parameters of water. Nonadiabatic effects seem to be larger than adiabatic ones for the structures of isotopologs of water. Therefore, the inverse route to Born-Oppenheimer or adiabatic equilibrium geometries is seriously compromised.

Another possibility for judging the computed adiabatic equilibrium geometries and the CVRQD PESs is offered by comparison of computed and experimental vibrationally averaged rotational constants. Spectroscopic vibration-rotation interaction constants, though apparently of very high precision, are somewhat phenomenological in nature and do not correspond very closely to the vibration-rotation interaction constants that can be obtained from a cubic force field representation of the PES via VPT2. The sizeable differences between the best $a b$ initio and the spectroscopic $\Delta A, \Delta B$, and $\Delta C$ values call attention to the fact that the accuracy of semispectroscopic equilibrium structures obtained through corrections of spectroscopic rotational constants by $a b$ initio vibration-rotation interaction constants might be compromised, at least for small and light species.

The quality of our results suggests that more studies of a similar nature are to be performed if really accurate values of Born-Oppenheimer, adiabatic, and spectroscopic equilibrium geometry parameters are needed. This recommendation is based on the fact that while the indirect, (semi)empirical route cannot eliminate all errors, the direct route, when feasible, is successful: theory is now capable of determining physically relevant adiabatic equilibrium structures, in the present case those of water, more accurately than can be meaningfully derived from available experimental data.

\section{Acknowledgements}

The work of AGC and VS has received a small amount of support from the Scientific Research Fund of Hungary (OTKA T047185 and T045955). This study originated during a stay of AGC in London, U.K. supported by a NATO Science Fellowship (3063/NATO/02). The work has also been supported by INTAS (03-51-3394), the UK Engineering and Physical Sciences Research Council, and the Russian Fund for Fundamental Studies. Our work greatly profited from useful discussions on certain aspects of the topic of this paper with Professors K. Kuchitsu, E. Hirota, J. Demaison, and B. T. Sutcliffe. We thank Drs. W. D. Allen and E. F. Valeev for their comments on the manuscript. This research is also part of an effort by a Task Group of the International Union of Pure and Applied Chemistry (IUPAC, Project no. 2003-024-1-100) to determine structures, vibrational frequencies, and thermodynamic 
functions of free radicals of importance in atmospheric chemistry.

[1] M. Born, J. R. Oppenheimer, Ann. Phys. 1927, 84, 457.

[2] M. Born, K. Huang, Dynamical Theory of Crystal Lattices, Oxford Univ. Press, New York, 1954.

[3] P. R. Bunker, P. Jensen, in Computational Molecular Spectroscopy, (Eds. P. Jensen, P. R. Bunker), Wiley, Chichester, 2000, pp. 3-11.

[4] P. G. Mezey, Potential Energy Hypersurfaces, Elsevier, New York, 1979.

[5] J. N. Murrell, S. Carter, S. C. Farantos, P. Huxley, A. J. C. Varandas, Molecular Potential Energy Surfaces, Wiley, New York, 1984.

[6] A. G. Császár, W. D. Allen, Y. Yamaguchi, H. F. Schaefer III, in Computational Molecular Spectroscopy, (Eds. P. Jensen, P. R. Bunker), Wiley, Chichester, 2000, pp. 15-68.

[7] H. Sellers, P. Pulay, Chem. Phys. Lett. 1984, 103, 463.

[8] N. C. Handy, Y. Yamaguchi, H. F. Schaefer III, J. Chem. Phys. 1986, 84, 4481.

[9] W. Kutzelnigg, Mol. Phys. 1997, 90, 909.

[10] D. W. Schwenke, J. Phys. Chem. A 2001, 105, 2352.

[11] E. F. Valeev, C. D. Sherrill, J. Chem. Phys. 2003, 118, 3921.

[12] J. K. G. Watson, J. Mol. Spectry. 2004, 223, 39.

[13] J. Demaison, G. Wlodarczak, H. D. Rudolph, in Advances in Molecular Structure Research, Vol. 3, JAI Press, 1997, pp. 1-51.

[14] L. Margules, J. Demaison, J. E. Boggs, J. Phys. Chem. A 1999, 103, 7632.

[15] J. Demaison, J. Breidung, W. Thiel, D. Papousek, Struct. Chem. 1999, 10, 129.

[16] K. Kuchitsu, Y. Morino, Bull. Chem. Soc. Japan 1965, 38, 805.

[17] K. Kuchitsu, S. J. Cyvin, in Molecular Structure and Vibrations, (Ed. S. J. Cyvin), Elsevier, Amsterdam, 1972, p. 183.

[18] K. Kuchitsu, in Accurate Molecular Structures: Their Determination and Importance, (Eds. A. Domenicano, I. Hargittai), Oxford University Press, Oxford, 1992, pp. 14-46.

[19] J. K. G. Watson, J. Mol. Spectry. 2004, 223, 39.

[20] M. Cafiero, L. Adamowicz, Chem. Phys. Lett. 2004, 387, 136.

[21] B. T. Sutcliffe, in Mathematical models and methods for ab initio quantum chemistry, Lecture Notes in Chemistry 74, (Eds. M. Defranceschi, C. le Bris), Springer, 2000, pp. 3-14.

[22] B. T. Sutcliffe, Int. J. Quant. Chem. 2002, 90, 66.

[23] E. K. Plyler, Phys. Rev. 1932, 39, 77.

[24] G. Herzberg, Molecular Spectra and Molecular Structure, Vol. II. 1945, van Nostrand: Toronto.

[25] W. S. Benedict, N. Gailar, E. K. Plyler, J. Chem. Phys. 1956, 24, 1139.

[26] K. Kuchitsu, L. S. Bartell, J. Chem. Phys. 1961, 36, 2460. 
[27] Landolt-Börnstein, New Series, Vol. II/7, Springer, Berlin, 1976.

[28] A. R. Hoy, P. R. Bunker, J. Mol. Spectry. 1979, 74, 1.

[29] M. Nakata, K. Kuchitsu, J. Mol. Struct. 1994, 320, 179.

[30] P. Jensen, S. A. Tashkun, V. G. Tyuterev, J. Mol. Spectry. 1994, 168, 271.

[31] H. Partridge, D. W. Schwenke, J. Chem. Phys. 1997, 106, 4618.

[32] S.V. Shirin, O.L. Polyansky, N.F. Zobov, P. Barletta, J. Tennyson, J. Chem. Phys. 2003, $118,2124$.

[33] K. Kuchitsu, K. Oyanagi, Faraday Discussions 1977, 62, 20.

[34] H. D. Rudolph, in Advances in Molecular Structure Research, Vol. 1, JAI Press, Greenwich, CT, 1995, p. 63.

[35] A. G. Császár, in Encyclopedia for Computational Chemistry, (Eds. P. v. R. Schleyer et al.), Wiley, Chichester, 1998, Vol. 1, pp. 13-30.

[36] W. Gordy, R. L. Cook, Microwave Molecular Spectra, Wiley, New York, 1984.

[37] W. D. Allen, E. Czinki, A. G. Császár, Chem. Eur. J. 2004, 10, 4512.

[38] J. M. L. Martin, Chem. Phys. Lett. 1998, 283, 283.

[39] J. M. L. Martin, Chem. Phys. Lett. 1998, 292, 411.

[40] B. Temelso, E. F. Valeev, C. D. Sherrill, J. Phys. Chem. A 2004, 108, 3068.

[41] W. Cencek, J. Rychlewski, R. Jaquet, W. Kutzelnigg, J. Chem. Phys. 1998, 108, 2831.

[42] O. L. Polyansky, A. G. Császár, S. V. Shirin, N. F. Zobov, P. Barletta, J. Tennyson, D. W. Schwenke, P. J. Knowles, Science 2003, 299, 539.

[43] G. Czakó, T. Furtenbacher, A. G. Császár, V. Szalay, Mol. Phys. 2004, 102, 2411.

[44] T. Furtenbacher, G. Czakó, A. G. Császár, V. Szalay, J. Chem. Phys. to be submitted.

[45] M. J. Bramley, T. Carrington, Jr. J. Chem. Phys. 1993, 99, 8519.

[46] J. Tennyson, M. A. Kostin, P. Barletta, G. J. Harris, O. L. Polyansky, J. Ramanlal, N. F. Zobov, Comp. Phys. Comm. 2004, 163, 85.

[47] T. H. Dunning, Jr., J. Chem. Phys. 1989, 90, 1007.

[48] The (aug-)cc-pVXZ basis sets were obtained from the Extensible Computational Chemistry Environment Basis Set Database, Version 1.0, as developed and distributed by the Molecular Science Computing Facility, Environmental and Molecular Sciences Laboratory, which is part of the Pacific Northwest Laboratory, P.O. Box 999, Richland, Washington 99352, USA and funded by the U.S. Department of Energy. The Pacific Northwest Laboratory is a multiprogram laboratory operated by Battelle Memorial Institute for the U.S. Department of Energy under contract DE-AC06-76RLO 1830.

[49] H.-J. Werner, P. J. Knowles, J. Chem. Phys. 1988, 89, 5803.

[50] MOLPRO (version 2002.1) is a package of ab initio electronic structure programs designed by H.-J. Werner and P. J. Knowles.

[51] R. J. Gdanitz, R. Ahlrichs, Chem. Phys. Lett. 1988, 143, 413.

[52] P. Pyykkö, Chem. Rev. 1988, 88, 563. 
[53] K. Balasubramanian, Relativistic effects in Chemistry, Part A: Theory and techniques and Part B: Applications, Wiley, New York, 1997.

[54] G. Tarczay, A. G. Császár, W. Klopper, H. M. Quiney, Mol. Phys. 2001, 99, 1769 and references cited therein.

[55] A. G. Császár, J. S. Kain, O. L. Polyansky, N. F. Zobov, J. Tennyson, Chem. Phys. Lett. 1998, 293, 317; 1999, 312, 613 (E).

[56] H. M. Quiney, P. Barletta, G. Tarczay, A. G. Császár, O. L. Polyansky, J. Tennyson, Chem. Phys. Lett. 2001, 344, 413.

[57] J. F. Stanton, J. Gauss, J. D. Watts, W. J. Lauderdale, and R. J. Bartlett, Int. J. Quantum Chem., Quantum Chem. Symp. 1992, 26, 897.

[58] The package also contains modified versions of the MOLECULE Gaussian integral program of J. Almlöf and P. R. Taylor, the ABACUS integral derivative program written by T. U. Helgaker, H. J. Aa. Jensen, P. Jørgensen and P. R. Taylor, and the PROPS property evaluation integral code of P. R. Taylor.

[59] Dalton, a molecular electronic structure program, Release 1.2 (2001), written by T. U. Helgaker, H. J. Aa. Jensen, P. Jørgensen, J. Olsen, K. Ruud, H. Agren, A. A. Auer, K.L. Bak, V. Bakken, O. Christiansen, S. Coriani, P. Dahle, E.K. Dalskov, T. Enevoldsen, B. Fernandez, C. Hättig, K. Hald, A. Halkier, H. Heiberg, H. Hettema, D. Jonsson, S. Kirpekar, R. Kobayashi, H. Koch, K. V. Mikkelsen, P. Norman, M.J. Packer, T. B. Pedersen, T. A. Ruden, A. Sanchez, T. Saue, S. P. A. Sauer, B. Schimmelpfennig, K. O. Sylvester-Hvid, P. R. Taylor, and O. Vahtras.

[60] H. M. Quiney, H. Skaane, I. P. Grant, Adv. Quant. Chem. 1999, 32, 1.

[61] I. P. Grant, H. M. Quiney, Int. J. Quant. Chem. 2000, 80, 283.

[62] H. A. Bethe, E. E. Salpeter, Quantum Mechanics of One- and Two-Electron Atoms, SpringerVerlag, Berlin, 1957.

[63] H. M. Quiney, H. Skaane, I. P. Grant, Chem. Phys. Lett. 1998, 290, 473.

[64] P. Pyykkö, K. Dyall, A. G. Császár, G. Tarczay, O. L. Polyansky, J. Tennyson, Phys. Rev. A 2001, 63, 024502.

[65] J. Tennyson, P. Barletta, M. A. Kostin, O. L. Polyansky, N. F. Zobov, Spectrochim. Acta 2002, $58 A, 663$.

[66] D. W. Schwenke, J. Phys. Chem. A 2001, 105, 2352.

[67] A. G. Császár, W. D. Allen, H. F. Schaefer III, J. Chem. Phys. 1998, 108, 9751.

[68] W. D. Allen, A. G. Császár, J. Chem. Phys. 1993, 98, 2983.

[69] A. G. Császár, W. D. Allen, J. Chem. Phys. 1996, 104, 2746.

[70] J. M. L. Martin, J. Chem. Phys. 1995, 242, 343.

[71] G. Tarczay, A. G. Császár, W. Klopper, V. Szalay, W. D. Allen, H. F. Schaefer III, J. Chem. Phys. 1999, 110, 11971.

[72] E. F. Valeev, W. D. Allen, H. F. Schaefer III, A. G. Császár, J. Chem. Phys. 2001, 114, 2875. 
[73] K. L. Bak, J. Gauss, P. Jørgensen, J. Olsen, T. Helgaker, J. F. Stanton, J. Chem. Phys. 2001, 114,6548 .

[74] A. Tajti, P. G. Szalay, A. G. Császár, M. Kállay, J. Gauss, E. F. Valeev, B. A. Flowers, J. Vazquéz, J. F. Stanton, J. Chem. Phys. 2004, 121, 11599.

[75] J. Tennyson, N. F. Zobov, R. Williamson, O. L. Polyansky, P. F. Bernath, J. Phys. Chem. Ref. Data 2001, 30, 735 .

[76] R. A. Toth, J. Opt. Soc. Am. B 1992, 9, 462.

[77] S. N. Mikhailenko, V. G. Tyuterev, G. Mellau, J. Mol. Spectry. 2003, 217, 195.

[78] R. A. Toth, J. Mol. Spectry. 1993, 162, 41.

[79] S.V. Shirin, O.L. Polyansky, N.F. Zobov, A. G. Császár, J. Tennyson, J. Chem. Phys. to be published.

[80] J. K. G. Watson, Mol. Phys. 1968, 15, 479.

[81] D. Kivelson, E. B. Wilson, J. Chem. Phys. 1953, 21, 1229.

[82] F. C. De Lucia, P. Helminger, R. L. Cook, W. Gordy, Phys. Rev. A 1972, 5, 487.

[83] A. V. Burenin, T. M. Fevral'skikh, E. N. Karyakin, O. L. Polyansky, S. M. Shapin, J. Mol. Spectry. 1983, 100, 182.

[84] S. P. Belov, I. N. Kozin, O. L. Polyansky, M. Yu. Tratyakov, N. F. Zobov, Opt. Spectry. 1987, 62, 735 .

[85] W. S. Benedict, S. A. Clough, L. Frenkel, T. E. Sullivan, J. Chem. Phys. 1970, 53, 2565.

[86] J. K. Messer, F. C. De Lucia, P. Helminger, J. Mol. Spectry. 1984, 105, 139.

[87] H. H. Nielsen, Rev. Mod. Phys. 1951, 23, 90.

[88] I. M. Mills, Molecular Spectroscopy: Modern Research, (Eds. K. N. Rao, C. W. Mathews), Academic Press, New York, 1972.

[89] P. Pulay, W. Meyer, J. E. Boggs, J. Chem. Phys. 1978, 68, 5077.

[90] D. A. Clabo, W. D. Allen, Y. Yamaguchi, R. B. Remington, H. F. Schaefer III, Chem. Phys. 1988, 123, 187.

[91] W. D. Allen, Y. Yamaguchi, A. G. Császár, D. A. Clabo, R. B. Remington, H. F. Schaefer III, Chem. Phys. 1990, 145, 427.

[92] C. Eckart, Phys. Rev. 1935, 47, 552.

[93] P. R. Bunker, P. Jensen, Molecular Symmetry and Spectroscopy, NRC Research Press, Ottawa, 1998.

[94] A. Ernesti, J. M. Hutson, Chem. Phys. Lett. 1994, 222, 257.

[95] A. G. Császár, I. M. Mills, Spectrochim. Acta 1997, 53A, 1101.

[96] F. Matsushima, H. Odashima, T. Iwasaki, S. Tsunekawa, K. Tagaki, J. Mol. Struct. 1995, 352, 371.

[97] F. Pawlowski,P. Jorgensen, J. Olsen, F. Hegelund, T. Helgaker, J. Gauss, K. L. Bak, J. F. Stanton, J. Chem. Phys. 2002, 116, 6482.

[98] D. Papousek, M. R. Aliev, Molecular Vibrational-Rotational Spectra, Elsevier, Amsterdam, 
1982.

[99] N. F. Zobov, O. L. Polyansky, C. R. Le Sueur, J. Tennyson, Chem. Phys. Lett. 260 (1996) 381.

[100] B. F. Burke, M. W. P. Strandberg, Phys. Rev. 1953, 90, 303.

[101] J. Verhoeven, A. Dymanus, J. Chem. Phys.1970, 52, 3222.

[102] K. Ruud, J. Vaara, J. Lounila, T. Helgaker, Chem. Phys. Lett. 1998, 297, 467.

[103] P. J. Wilson, R. D. Amos, N. C. Handy, J. Mol. Struct. (THEOCHEM) 2000, 506, 335.

[104] J. K. G. Watson, J. Mol. Spectry. 1973, 45, 99.

[105] E. Tiemann, J. F. Ogilvie, J. Mol. Spectry. 1994, 165, 377.

[106] J. F. Ogilvie, Chem. Phys. Lett. 1997, 267, 590.

[107] R. J. Le Roy, Y. Huang, J. Mol. Struct. (THEOCHEM) 2002, 591, 175.

[108] I. Morino, K. Matsumura, K. Kawaguchi, J. Mol. Spectry. 1995, 174, 123.

[109] M. Zachwieja, J. Mol. Spectry. 1995, 170, 285.

[110] T. Amano, J. Mol. Spectry. 1984, 103, 436.

[111] R. Colin, P. F. Coheur, M. Kiseleva, A. C. Vandaele, P. F. Bernath, J. Mol. Spectry. 2002, $214,225$.

[112] M. C. Abrams, S. P. Davis, M. L. P. Rao, R. Engleman, J. Mol. Spectry. 1994, 165, 57. 
Table 1

Brief history of the mass-independent spectroscopic equilibrium structure of water. ${ }^{a}$

\begin{tabular}{lccl}
\hline Year & $r_{\mathrm{e}}$ & $\theta_{\mathrm{e}}$ & \multicolumn{1}{c}{ Comment } \\
\hline 1932 & - & 115 & Ref. [23] $^{b}$ \\
1945 & $0.958_{4}$ & 104.45 & Ref. [24] \\
1956 & $0.9572(3)$ & $104.52(5)$ & Ref. [25] \\
1961 & $0.956_{1}$ & 104.57 & Ref. [26] \\
1976 & 0.9575 & 104.51 & Landolt-Börnstein [27] $]^{e}$ \\
1979 & & 104.48 & Ref. [28] \\
1994 & 0.9578 & 104.48 & Ref. [29] \\
1994 & $0.95785(3)$ & $104.542(9)$ & Ref. [30] \\
1997 & 0.95767 & 104.482 & Ref. [31], ab initio PES. \\
1997 & 0.95783 & 104.509 & Ref. [31], fitted empirical PES. \\
2003 & 0.95782 & 104.499 & Ref. [32], fitted PES of $\mathrm{H}_{2}{ }^{16} \mathrm{O}$ \\
\hline
\end{tabular}

${ }^{a}$ Bond length, $r_{\mathrm{e}}$, in angstrom, bond angle, $\theta_{\mathrm{e}}$, in degrees.

${ }^{b}$ Obtained from the fundamental frequencies of water assumed to be 5309, 1597, and $3742 \mathrm{~cm}^{-1}$ and through the use of an equation derived by Dennison (D. M. Dennison, Phil. Mag. 1926, 1, 195).

${ }^{c}$ Based upon careful analysis of results due to Mecke and co-workers (R. Mecke, Z. Physik 1933, 81, 313; W. Baumann, R. Mecke, Z. Physik 1933, 81, 445; K. Freudenberg, R. Mecke, Z. Physik 1933, 81, 465), Darling and Dennison (B. T. Darling, D. M. Dennison, Phys. Rev. 1940, 57, 128), and Nielsen (H. H. Nielsen, Phys. Rev. 1941, 59, 565; H. H. Nielsen, Phys. Rev. 1942, 62, 422).

${ }^{d}$ Benedict et al. [25] reported equilibrium structures not only for $\mathrm{H}_{2}{ }^{16} \mathrm{O}$ but also for $\mathrm{HD}^{16} \mathrm{O}$ and $\mathrm{D}_{2}{ }^{16} \mathrm{O}$, after inclusion of electronic motion effects into the moments of inertia. The $\mathrm{D}_{2}{ }^{16} \mathrm{O}$ structural parameters differ from the equilibrium structural parameters of $\mathrm{H}_{2}{ }^{16} \mathrm{O}$ by $+0.0003 \AA$ and $-0.049^{\circ}$. These differences are about an order of magnitude larger than those obtained in the present study ( $c f$. Table 4$)$.

${ }^{e}$ Kuchitsu and Bartell also reported structural estimates for $\mathrm{D}_{2}{ }^{16} \mathrm{O}$, as well, with $r_{\mathrm{e}}=$ $0.957_{0} \AA$ and $\theta_{\mathrm{e}}=104.43^{\circ}$. The results reported were obtained from the rotational constants of Benedict et al. [25] and the vibration-rotation interaction constants determined in ref. [26].

$f$ These values are based on ground-state constants from Cook et al. (R. L. Cook, F. C. De Lucia, P. Helminger, J. Mol. Spectry. 1974, 53, 62) and on vibration-rotation interaction constants from Ref. [25]. 
Table 2

Born-Oppenheimer and adiabatic equilibrium structures of water from $a b$ initio electronic structure computations. ${ }^{a}$

\begin{tabular}{lccl}
\hline Level of theory/correction & $r_{\mathrm{e}}$ & $\theta_{\mathrm{e}}$ & Comment \\
\hline aug-cc-pV5Z ICMRCI & 0.95875 & 104.387 & Ref. [42] \\
aug-cc-pV6Z ICMRCI & 0.95870 & 104.411 & Ref. [42] \\
CBS ICMRCI & 0.95862 & 104.422 & Ref. [42] \\
core correlation & -0.00096 & +0.134 & Ref. [31, 42] \\
relativistic Breit & +0.00016 & -0.074 & Ref. [42, 55, 56] \\
quantum electrodynamics & $<10^{-5}$ & +0.003 & Ref. [42, 64] \\
best mass-independent ab initio & 0.95782 & 104.485 & this work, Ref. [42] \\
adiabatic correction $\left(\mathrm{H}_{2}{ }^{16} \mathrm{O}\right)$ & +0.00003 & +0.015 & Ref. [42] \\
best mass-dependent $a b$ initio $\left(\mathrm{H}_{2}{ }^{16} \mathrm{O}\right)$ & 0.95785 & 104.500 & this work, Ref. [42] \\
\hline
\end{tabular}

${ }^{a}$ Bond length $\left(r_{\mathrm{e}}\right)$ in angstrom, bond angle $\left(\theta_{\mathrm{e}}\right)$ in degrees. The ICMRCI calculations are valence-only (freezing the 1 s core orbital of $\mathrm{O}$ ). CBS $=$ complete basis set. 
Table 3

$J=1$ and 2 rotational term values $\left(J_{K_{a} K_{c}}\right)$, in $\mathrm{cm}^{-1}$, for the ground vibrational states of water isotopologs. ${ }^{a}$

\begin{tabular}{|c|c|c|c|c|c|c|}
\hline & \multicolumn{3}{|c|}{$\mathrm{H}_{2}{ }^{16} \mathrm{O}$} & \multicolumn{3}{|c|}{$\mathrm{H}_{2}{ }^{17} \mathrm{O}$} \\
\hline & CVRQD & Fitted & Expt. $^{b}$ & CVRQD & Fitted & Expt. $^{c}$ \\
\hline $1_{01}$ & 23.795 & 23.794 & 23.7944 & 23.774 & 23.774 & 23.7735 \\
\hline $1_{11}$ & 37.138 & 37.137 & 37.1371 & 36.931 & 36.931 & 36.9311 \\
\hline $1_{10}$ & 42.372 & 42.372 & 42.3717 & 42.187 & 42.187 & 42.1869 \\
\hline $2_{02}$ & 70.094 & 70.091 & 70.0908 & 70.007 & 70.005 & 70.0047 \\
\hline $2_{12}$ & 79.499 & 79.496 & 79.4964 & 79.229 & 79.227 & 79.2273 \\
\hline $2_{11}$ & 95.178 & 95.176 & 95.1759 & 94.973 & 94.971 & 94.9705 \\
\hline $2_{21}$ & 134.903 & 134.901 & 134.9016 & 134.146 & 134.145 & 134.1453 \\
\hline \multirow[t]{3}{*}{$2_{20}$} & 136.166 & 136.164 & 136.1639 & 135.432 & 135.431 & 135.4312 \\
\hline & & $\mathrm{H}_{2}{ }^{18} \mathrm{O}$ & & & $\mathrm{D}_{2}{ }^{16} \mathrm{O}$ & \\
\hline & CVRQD & Fitted & Expt. $^{d}$ & CVRQD & Fitted & Expt. ${ }^{e}$ \\
\hline $1_{01}$ & 23.756 & 23.755 & 23.7549 & 12.117 & 12.117 & 12.117 \\
\hline $1_{11}$ & 36.749 & 36.749 & 36.7486 & 20.257 & 20.258 & 20.258 \\
\hline $1_{10}$ & 42.024 & 42.023 & 42.0234 & 22.682 & 22.683 & 22.683 \\
\hline $2_{02}$ & 69.930 & 69.927 & 69.9274 & 35.877 & 35.878 & 35.878 \\
\hline $2_{12}$ & 78.991 & 78.989 & 78.9886 & 42.067 & 42.068 & 42.068 \\
\hline $2_{11}$ & 94.791 & 94.789 & 94.7886 & 49.337 & 49.338 & 49.338 \\
\hline $2_{21}$ & 133.478 & 133.476 & 133.4758 & 73.669 & 73.672 & 73.672 \\
\hline $2_{20}$ & 134.785 & 134.783 & 134.7830 & 74.135 & 74.137 & 74.137 \\
\hline
\end{tabular}

${ }^{a} 1 \mathrm{~cm}^{-1}=2.99792458 \times 10^{4} \mathrm{MHz}$. The ab initio CVRQD PESs are taken from Ref. [42]. The fitted PESs for $\mathrm{H}_{2}{ }^{16} \mathrm{O}, \mathrm{H}_{2}{ }^{17} \mathrm{O}$, and $\mathrm{H}_{2}{ }^{18} \mathrm{O}$ are due to Shirin et al. [79]. The fitted PES used for $\mathrm{D}_{2} \mathrm{O}$ is from S. V. Shirin, N. F. Zobov, O. L. Polyansky, J. Tennyson, T. Parekunnel and P. F. Bernath, J. Chem. Phys. 2004, 120, 206. Nuclear masses, in u, used in the calculations and in the determination of the adiabatic correction surfaces: $m(\mathrm{H})$ $=1.007276, m(\mathrm{D})=2.013553, m\left({ }^{16} \mathrm{O}\right)=15.990526, m\left({ }^{17} \mathrm{O}\right)=16.994742$, and $m\left({ }^{18} \mathrm{O}\right)=$ 17.994771 .

${ }^{b}$ Ref. [75].

${ }^{c}$ Ref. [76].

${ }^{d}$ Ref. [77].

e Ref. [78]. 
Table 4

Isotopic effects, based on the CVRQD potential, on the equilibrium structural parameters of water isotopologs. ${ }^{a}$

\begin{tabular}{lcc}
\hline & $\Delta r_{\mathrm{e}}$ & $\Delta \theta_{\mathrm{e}}$ \\
\hline $\mathrm{H}_{2}{ }^{17} \mathrm{O}$ & $<10^{-6}$ & $<10^{-3}$ \\
$\mathrm{H}_{2}{ }^{18} \mathrm{O}$ & $<10^{-6}$ & $<10^{-3}$ \\
$\mathrm{D}_{2}{ }^{16} \mathrm{O}$ & -0.000019 & -0.010 \\
\hline
\end{tabular}

${ }^{a}$ Bond lengths in angstrom, bond angles in degrees. The underlying mass-dependent equilibrium structure of $\mathrm{H}_{2}{ }^{16} \mathrm{O}$ is $r_{\mathrm{e}}^{\mathrm{ad}}\left({ }^{16} \mathrm{OH}\right)=0.957854 \AA$ and $\theta_{\mathrm{e}}^{\text {ad }}\left(\mathrm{H}^{16} \mathrm{OH}\right)=$ $104.500^{\circ}$, as given in Table 2. The geometry parameters obtained from the empirical potential [79] are the same as those given above within the claimed precision. It is basically meaningless to give further digits in the reported geometry parameters as they would not represent the underlying $a b$ initio values accurately due to loss of precision caused by the fitting of the DBOC surfaces. 
Table 5

Effective ground-state rotational constants $\left(A_{0}, A_{0}^{\prime}, B_{0}, B_{0}^{\prime}, C_{0}\right.$ and $C_{0}^{\prime}$, in $\left.\mathrm{MHz}\right)$, ground-state inertia defects $\left(\Delta_{\mathrm{pl}}^{0}\right.$, in $\left.\mathrm{u}^{2}\right)$, and differences between effective and equilibrium rotational constants $(\Delta A, \Delta B$, and $\Delta C$, in $\mathrm{MHz})$, in the ground vibrational states of symmetric isotopologs of water. ${ }^{a}$

\begin{tabular}{|c|c|c|c|}
\hline Isotopomer & $\mathrm{H}_{2}{ }^{16} \mathrm{O}$ & $\mathrm{H}_{2}{ }^{18} \mathrm{O}$ & $\mathrm{D}_{2}{ }^{16} \mathrm{O}$ \\
\hline \multicolumn{4}{|c|}{ Measured(Spectroscopy [82-86]) $)^{b, c}$} \\
\hline$A_{0}$ & 835839.9 & 825367.32 & 462292.4 \\
\hline$A_{0}^{\prime}$ & 835783.3 & & \\
\hline$B_{0}$ & 435354.5 & 435353.81 & 217979.9 \\
\hline$B_{0}^{\prime}$ & 435044.5 & & \\
\hline$C_{0}$ & 278133.3 & 276950.50 & 145303.3 \\
\hline$C_{0}^{\prime}$ & 278446.9 & & \\
\hline$\Delta_{\mathrm{pl}}^{0}$ & 0.04864 & 0.05164 & 0.06643 \\
\hline$\Delta A$ & 14960 & & 4887 \\
\hline$\Delta B$ & -2248 & & -809 \\
\hline$\Delta C$ & -7165 & & -2698 \\
\hline \multicolumn{4}{|c|}{ Computed (CVRQD PES [42]) } \\
\hline$A_{0}$ & 835390.0 & 824928.7 & 462097.8 \\
\hline$\Delta A$ & 14400.4 & 14162.2 & 5463.5 \\
\hline$B_{0}$ & 434825.1 & 434835.4 & 217894.7 \\
\hline$\Delta B$ & -2286.1 & -2272.8 & -866.3 \\
\hline$C_{0}$ & 278699.4 & 277502.6 & 145436.5 \\
\hline$\Delta C$ & -6543.1 & -6494.4 & -2467.7 \\
\hline$\Delta_{\mathrm{pl}}^{0}$ & 0.04613 & 0.04631 & 0.06188 \\
\hline \multicolumn{4}{|c|}{ Computed (Fitted PES [79]) } \\
\hline$A_{0}$ & 835433.6 & 824971.1 & 462006.6 \\
\hline$\Delta A$ & 14444.0 & 14204.5 & 5390.5 \\
\hline$B_{0}$ & 434825.2 & 434835.5 & 217917.4 \\
\hline$\Delta B$ & -2286.0 & -2272.7 & -835.0 \\
\hline$C_{0}$ & 278703.3 & 277506.5 & 145438.0 \\
\hline$\Delta C$ & -6539.1 & -6490.5 & -2460.3 \\
\hline$\Delta_{\mathrm{pl}}^{0}$ & 0.04613 & 0.04631 & 0.06187 \\
\hline \multicolumn{4}{|c|}{ Computed (VPT2 [95]) ${ }^{d}$} \\
\hline$\Delta A$ & 11690 & & \\
\hline$\Delta B$ & -2700 & & \\
\hline$\Delta C$ & -7050 & & \\
\hline$\Delta_{\mathrm{pl}}^{0}$ & 0.04631 & & \\
\hline
\end{tabular}


Table 5 cont.

${ }^{a} 1 \mathrm{~cm}^{-1}=2.99792458 \times 10^{4} \mathrm{MHz}$ and $h / 8 \pi^{2} c=505379 \mathrm{MHzu} \AA^{2} . \Delta_{\mathrm{pl}}^{0}=I_{\mathrm{c}}-I_{\mathrm{a}}-I_{\mathrm{b}}$, where $I_{\alpha}, \alpha=\mathrm{a}, \mathrm{b}, \mathrm{c}$, is the appropriate moment of inertia. Atomic masses have been employed in the calculations. Note that during the refinement of the $\mathrm{H}_{2}{ }^{16} \mathrm{O} \operatorname{PES} m\left({ }^{16} \mathrm{O}\right)=15.990726 \mathrm{u}$ has been employed.

${ }^{b} A_{0}^{\prime}, B_{0}^{\prime}$, and $C_{0}^{\prime}$ values are only available for $\mathrm{H}_{2}{ }^{16} \mathrm{O}$. For the other isotopologs contributions from the distortion terms have not been removed hindering direct comparison with the computed values.

${ }^{c}$ The $\Delta A, \Delta B$, and $\Delta C$ values reported correspond to vibration-rotation interaction constants taken from Ref. [25]. The calc. II $\Delta A, \Delta B$, and $\Delta C$ values of Kuchitsu and Bartell [26] are 10500, -3300 , and $-7800 \mathrm{MHz}$ for $\mathrm{H}_{2}{ }^{16} \mathrm{O}$ and $4500,-1200$, and $-2700 \mathrm{MHz}$ for $\mathrm{D}_{2}{ }^{16} \mathrm{O}$.

${ }^{d}$ VPT2 = second-order vibrational perturbation theory. The underlying vibrationrotation interaction constants correspond to Set III of Table 4 of Ref. [95]. 
Table 6

Spectroscopic equilibrium structural parameters for two isotopologs of water obtained using different ground-state rotational constants $\left(A_{0}^{\prime}\right.$ and $\left.B_{0}^{\prime}\right)$, rotational constant corrections $\left(\Delta A_{0}\right.$ and $\left.\Delta B_{0}\right)$, and atomic masses.

\begin{tabular}{lccccc}
\hline & & \multicolumn{3}{c}{$\mathrm{H}_{2}{ }^{16} \mathrm{O}$} & $\mathrm{D}_{2}{ }^{16} \mathrm{O}$ \\
$A_{0}^{\prime}, B_{0}^{\prime}$ & $\Delta A, \Delta B$ & $r_{\mathrm{e}}$ & $\theta_{\mathrm{e}}$ & $r_{\mathrm{e}}$ & $\theta_{\mathrm{e}}$ \\
\hline CVRQD CVRQD & 0.957854 & 104.500 & 0.957834 & 104.490 \\
Expt. $^{a}$ & CVRQD $^{a}$ & 0.957618 & 104.499 & 0.957567 & 104.483 \\
Expt. $^{a}$ & Expt. $^{b}$ & 0.957766 & 104.483 & & \\
\hline
\end{tabular}

${ }^{a}$ Ref. [82] for $\mathrm{H}_{2}{ }^{16} \mathrm{O}$ and Ref. [85] for $\mathrm{D}_{2}{ }^{16} \mathrm{O}$, see Table 5 for the numerical values. No correction for centrifugal distortion effects is made in the case of the $\mathrm{D}_{2}{ }^{16} \mathrm{O}$ rotational constants, so they do not correspond to $A_{0}^{\prime}$ and $B_{0}^{\prime}$. Only the $A_{0}$ and $B_{0}$ combination is used here as these rotational constants are unaffected by the Coriolis effect (for further discussion see Tables 13.10 and 13.18 of Ref. [36]).

${ }^{b}$ Ref. [25]. 